УДК 621.37:51-74

\title{
ПАРАМЕТРИЧЕСКИЙ СПЕКТРАЛЬНЫЙ АНАЛИЗ ЗАШУМЛЕННЫХ СИГНАЛОВ С УНИМОДАЛЬНЫМ СПЕКТРОМ
}

\author{
В. Г. АНДРЕЕВ ${ }^{1}$, Н. Л. ЧАН ${ }^{1}$, Т. Ф. НГУЕН ${ }^{2}$ \\ ${ }^{1}$ Рязанский государственный радиотехнический университет, \\ Россия, Рязань, 390005, ул. Гагарина, д. 59/1 \\ ${ }^{2}$ Вьетнамский государственный технический университет им. Ле Куй Дона, \\ Вьетнам, Ханой, ул. Хоанг Куок Вьет, 236
}

\begin{abstract}
Аннотация. Предложен метод восстановления коэффициентов дискретной автокорреляционной функции случайных сигналов с унимодальной спектральной плотностью мощности для построения их параметрических моделей. Метод базируется на нахождении оптимальных значений относительной ширины $\Delta F T$ и весового коэффициента $\alpha \in[0 ; 1]$ спектральной моды, характеризующего доли гауссовской и резонансной составляющих в огибающей спектра. Предлагаемый метод дает возможность уменьшить в 1,5-4 раза невязку между контрольным и оцениваемым спектрами по сравнению с известными подходами к параметрическому спектральному анализу. Увеличение адекватности спектрального оценивания дает возможность сократить в 2,3-4 раза длину $M$ анализируемой временной выборки при сохранении достигаемой другими известными параметрическими методами точности спектрального анализа. Выигрыши достигаются за счет использования априорной информации о спектральных свойствах анализируемого процесса.
\end{abstract}

Ключевые слова: спектр; спектральное оценивание; дискретная автокорреляционная функция; авторегрессионная модель; авторегрессия; спектральная плотность мощности; параметрические оценки

В настоящее время в различных областях радиотехники существует проблема уменьшения влияния шумов, осложняющих спектральное оценивание квазистационарных сигналов в различных прикладных областях $[1,2,17]$. Решение этой задачи характерно для параметрического спектрального анализа, основанного на восстановленных коэффициентах автокорреляционной функции [3, 4].

Подобное восстановление возможно в тех задачах, где спектральная плотность мощности (СПМ) исходных, не подверженных влиянию шумов, сигналов имеет унимодальный вид с частично известными параметрами спектральной моды. К таким задачам можно отнести обработку и оценивание параметров отражений электромагнитных волн от протяжен- ных объектов (облачность, туман, стаи птиц и насекомых, пылевые облака, подстилающая поверхность), а также техническую и медицинскую диагностику $[3,5,18,19]$.

Отметим, что существует возможность путем нахождения оптимальных значений относительной ширины $\triangle F T(F-$ частота, $T$ - период времени между выборками) спектральной моды и весового коэффициента $\alpha$, характеризующего долю гауссовской и долю $(1-\alpha)$ резонансной составляющих в огибающей унимодального спектра, компенсировать деструктивное воздействие аддитивного белого гауссовского шума на оценку автокорреляционных свойств экспериментального сигнала $[1,21$, 22]. 


\section{БИБЛИОГРАФИЧЕСКИЙ СПИСОК}

1. Марпл-мл., С. Л. Цифровой спектральный анализ и его приложения. Пер. с англ. М.: Мир, 1990. 584 с.

2. Андреев, В.Г. “Оптимизация авторегрессионных моделей мешающих радиоотражений,” Известия вузов. Радиоэлектроника, Т. 51, № 7, С. 40-47, 2008. URI: http://radio.kpi.ua/article/view/S00213470080700 42.

3. Андреев, В. Г.; Чан, Н. Л.; Белокуров, В. А. "Параметрический спектральный анализ зашумленных сигналов с гауссовской формой спектра," Вестник Рязанского государственного радиотехнического университета, № 55, С. 16-21, 2016. DOI: https://doi.org/10.21667/1995-4565-2016-58-4-24-29.

4. Kay, S. M.; Marple Jr., S. L. 'Spectrum analysis-A modern perspective," Proc. IEEE, Vol. 69, No. 11, p. 1380-1419, 1981. DOI: 10.1109/PROC.1981.12184.

5. Андреев, В.Г.; Нгуен, Т.Ф. “Обработка кардиосигналов на фоне комбинированных помех," Вестник Рязанского государственного радиотехнического университета, № 48, C. 60-64, 2014. URI: https://elibrary.ru/item.asp?id=21724317.

6. Бакулев, П.А.; Кошелев, В.И.; Андреев, В.Г. “Оптимизация АРСС-моделирования эхо-сигналов,» Известия вузов. Радиоэлектроника, Т. 37, № 9, С. 3 8, 1994.

7. Андреев, В. Г.; Чан, Н. Л. “Синтез модифицированной переопределённой авторегрессионной модели по короткой выборке случайного процесса," Вестник Рязанского государственного радиотехнического университета, № 54, C. 45-49, 2015. URI: https://elib rary.ru/item.asp? $\mathrm{id}=25588818$.

8. Akaike, H. "Power spectrum estimation through autoregressive model fitting," Ann. Inst. Stat. Math., Vol. 21, p. 407-419, 1969. DOI: 10.1007/BF02532269.

9. Кошелев, В.И. АРСС-модели случайных проиессов. Прикладные задачи синтеза и оптимизации. М.: Радио и связь, 2002. 112 с.

10. Андреев, В.Г. “Оптимизация авторегрессионных моделей радиоотражений,” Вестник Рязанского государственного радиотехнического университета, 
№ 35, C. 12-15, 2011. URI: https://elibrary.ru/item.asp? $\mathrm{id}=15617928$.

11. Андреев, В.Г.; Нгуен, В.Ш. "Параметрическое моделирование коррелированных радиоотражений для анализа эффективности обработки эхо-сигналов," Вестник Рязанского государственного радиотехнического университета, № 18, С. 40-45, 2006. URI: https://elibrary.ru/item.asp?id=11743408.

12. Кошелев, В.И.; Андреев, В.Г. “Синтез АРСС-моделей эхо-сигналов," Известия вузов. Радиоэлектроника, Т. 36, № 7, С. 8 13, 1993.

13. Tuuk, Peter B.; Marple, S. Lawrence. "Compressed sensing radar amid noise and clutter using interference covariance information," IEEE Trans. Aerospace Electronic Syst., Vol. 50, No. 2, p. 887-897, Apr 2014. DOI: 10.1109/TAES.2014.120523.

14. Андреев, В.Г.; Нгуен, Ш.В. “Оптимизация фильтров моделирования мешающих радиоотражений для исследования систем первичной обработки эхо-сигналов," Известия вузов. Радиоэлектроника, Т. 49, № 10, C. 69-76, 2006. URI: http://radio.kpi.ua/article/ view/S0021347006100074

15. Горелик, А.Г.; Коломиец, С.Ф.; Куприянов, П.В. “Форма спектра рассеянного поля как источник информации о рассеивающей среде и протекающих в ней динамических процессах," Научный вестник МГТУ ГА. Серия Радиофизика и электроника, № 176, C. $18,2012$.

16. Коломиец, С. Ф. “Интерпретация Z-R соотношения в дождях на конечных периодах времени изме- рения с учетом условий рассеяния Ми," Усnехи современной радиоэлектроники, № 12, C. 51-61, 2007. URI: http://www.radiotec.ru/article/2154.

17. Dmytro M. Piza, T. I. Bugrova, V. N. Lavrentiev, Dmytro S. Semenov. "Method of forming classified training sample in case of spacial signal processing under influence of combined interference". Radioelectronics and Communications Systems. Vol 61, No. 7, pp.420-428, 2018. DOI: $\underline{10.3103 / \mathrm{S} 0}$ 735272718070051

18. David I. Lekhovytskiy. "Adaptive lattice filters for systems of space-time processing of non-stationary Gaussian processes". Radioelectronics and Communications Systems. Vol 61, No. 11, pp.477-514, 2018. DOI: $\underline{10.3103 / \mathrm{S} 0735272718}$ $\underline{110018}$

19. V. A. Dvinskikh, K. A. Razumikhin."Spectral analysis of digital quasiperiodic signals". Radioelectronics and Communications Systems. Vol 48, No. 8, pp.14-17, 2005. DOI: 10.3103/S0735272705080030.

20. V. G. Andrejev, Nguyen Tien Phat. "Adaptive processing of signals on a background of clutter and noise". Radioelectronics and Communications Systems. Vol 58, No. 2, pp.48-53, 2015. DOI: 10.3103/S0735272715020053.

21. K. V. Bisina ; Maleeha Abdul Azeez. "Optimized estimation of power spectral density". 2017 International Conference on Intelligent Computing and Control Systems (ICICCS). IEEE. DOI: 10.1109/ICCONS.2017.8250588.

22. Valentina M. Pukhova; Taras V. Kustov; Gabriele Ferrini. "Time-frequency analysis of non-stationary signals". 2018 IEEE Conference of Russian Young Researchers in Electrical and Electronic Engineering (EIConRus). IEEE. DOI: 10.1109/EIConRus.2018.8317292. 